University of Nebraska - Lincoln

DigitalCommons@University of Nebraska - Lincoln

2000

\title{
Pore fluid pressure, apparent friction, and Coulomb failure
}

N. M. Beeler

U.S. Geological Survey

R. W. Simpson

U.S. Geological Survey

S. H. Hickman

U.S. Geological Survey

D. A. Lockner

U.S. Geological Survey

Follow this and additional works at: https://digitalcommons.unl.edu/usgsstaffpub

Part of the Earth Sciences Commons

Beeler, N. M.; Simpson, R. W.; Hickman, S. H.; and Lockner, D. A., "Pore fluid pressure, apparent friction, and Coulomb failure" (2000). USGS Staff -- Published Research. 412.

https://digitalcommons.unl.edu/usgsstaffpub/412

This Article is brought to you for free and open access by the US Geological Survey at DigitalCommons@University of Nebraska - Lincoln. It has been accepted for inclusion in USGS Staff -- Published Research by an authorized administrator of DigitalCommons@University of Nebraska - Lincoln. 


\title{
Pore fluid pressure, apparent friction, and Coulomb failure
}

\author{
N.M. Beeler, R.W. Simpson, S.H. Hickman, and D.A. Lockner \\ U.S. Geological Survey, Menlo Park, California
}

\begin{abstract}
Many recent studies of stress-triggered seismicity rely on a fault failure model with a single free parameter, the apparent coefficient of friction, presumed to be a material constant with possible values $0 \leq \mu^{\prime} \leq 1$. These studies may present a misleading view of fault strength and the role of pore fluid pressure in earthquake failure. The parameter $\mu^{\prime}$ is intended to incorporate the effects of both friction and pore pressure, but is a material constant only if changes in pore fluid pressure induced by changes in stress are proportional to the normal stress change across the potential failure plane. Although specific models of fault zones permit such a relation, neither is it known that fault zones within the Earth behave this way, nor is this behavior expected in all cases. In contrast, for an isotropic homogeneous poroelastic model the pore pressure changes are proportional to changes in mean stress, $\mu^{\prime}$ is not a material constant, and $-\infty \leq \mu^{\prime} \leq+\infty$. Analysis of the change in Coulomb failure stress for tectonically loaded reverse and strike-slip faults shows considerable differences between these two pore pressure models, suggesting that such models might be distinguished from one another using observations of triggered seismicity (e.g., aftershocks). We conclude that using the constant apparent friction model exclusively in studies of Coulomb failure stress is unwise and could lead to significant errors in estimated stress change and seismic hazard.
\end{abstract}

\section{Introduction}

Studies of triggered seismicity have used the stress changes produced by a large earthquake (source earthquake) to explain the spatial distribution of subsequent earthquakes (target earthquakes) in the surrounding region. Such studies commonly assume that target earthquakes obey the Coulomb failure criterion and that changes in proximity to failure of a particular fault plane can be determined if the stress changes are known (see summary by Harris, [1998]). The change in proximity to failure is the change in Coulomb failure stress

$$
\Delta \sigma_{c}=\Delta \tau_{r}-\mu\left(\Delta \sigma_{n}-\Delta p\right)
$$

where $\Delta \tau_{r}$ is the change in shear stress on the plane in the expected rake (slip) direction on the target fault, $\Delta \sigma_{n}$ is the change in normal stress (compression is positive), $\mu$ is the coefficient of friction, and $\Delta p$ is the change in pore fluid pressure [Harris and Simpson, 1992]. Positive values of $\Delta \sigma_{c}$ indicate that the fault plane in question is closer to failure, whereas negative values indicate stress changes that move the fault farther from failure. The stress changes used to evaluate $\Delta \sigma_{c}$ with (1) are commonly calculated from dislocation models of

This paper is not subject to U.S. copyright. Published in 2000 by the American Geophysical Union.

Paper number 2000JB900119. the source earthquake slip, assuming the surroundings are linearly elastic.

It is often further assumed that pore pressure changes induced by the change in stress state can be combined with friction into a single parameter $\mu^{\prime}$, the apparent coefficient of friction, such that (1) is replaced by

$$
\Delta \sigma_{c}=\Delta \tau_{r}-\mu^{\prime} \Delta \sigma_{n},
$$

and $\mu^{\prime}$ replaces both $\mu$ and $\Delta p$. The parameter $\mu^{\prime}$ is then treated as if it were a material constant, independent of the tectonic environment (faulting regime), the magnitude of the stress changes, and time.

The purpose of the present study is to illuminate potential problems resulting from using (2) assuming constant apparent friction (the constant apparent friction model) as the earthquake failure criterion in studies of triggered seismicity. There are three issues we will address: (1) whether there are theoretical or observational bases for the constant apparent friction model, (2) whether changes in Coulomb failure stress depend significantly on choice of pore pressure model, and (3) whether previous studies of triggered seismicity might be in error due to using the constant apparent friction model. We find that the constant apparent friction model is neither general nor is it supported directly by experimental or field observations. To address whether calculated changes in Coulomb failure stress are sensitive to assumptions about pore pressure, we compare 
the predictions of the constant apparent friction model with that of a second pore pressure hypothesis, namely equation (1) assuming homogeneous isotropic poroelasticity. To make our comparison simple and hopefully intuitive, we determine the predictions of these two models for conditions of increasing tectonic stress (varying a single principal stress) in reverse and strike-slip faulting environments. The principal conclusions of our study derive from these tectonic loading examples. However, our examples of tectonic stress change are difficult to relate to the earthquake-induced stress changes considered in most previous studies of stress-triggered seismicity. To address the third issue we therefore provide an actual field example of earthquake-induced stress change where the choice of pore pressure model affects the failure stress on seismogenic faults: the change of failure stress on central California faults resulting from stress changes produced by the 1989 Loma Prieta earthquake.

\section{Coulomb Failure and the Law of Effective Stress}

Coulomb [1773] suggested that shear failure occurs when the shear stress $\tau$ acting across a plane reaches a value

$$
|\vec{\tau}|=C+\mu \sigma_{n}
$$

where $C$ is the cohesion of the material and $\mu$ is the coefficient of internal friction. A similar relation named Amontons law has been found to describe initiation of sliding on preexisting planes where $\mu$ is the coefficient of friction [Jaeger and Cook, 1979]. In the presence of pore fluid with pressure $p$, equation (3) must be amended in accord with the effective stress law [Terzhagi, 1923], yielding

$$
|\vec{\tau}|=C+\mu\left(\sigma_{n}-p\right) .
$$

Field studies confirm the validity of (4) for faults [Raleigh et al., 1976; Zoback and Healy, 1984; Townend and Zoback, 2000]. As a measure of proximity to failure, the Coulomb failure stress $\sigma_{c}$ (also referred to in some studies as the Coulomb failure function, $C F F$ [Harris and Simpson, 1992], or as CFS [Harris et al., 1995]) can be defined as

$$
\sigma_{c}=|\vec{\tau}|-\mu\left(\sigma_{n}-p\right)-C .
$$

Negative values of $\sigma_{c}$ imply that the failure threshold has not yet been reached; zero or positive values imply that the failure threshold has been reached or exceeded. If $C$ remains constant, then the change in $\sigma_{c}$ produced on a plane by a nearby earthquake or other stress perturbation is

$$
\Delta \sigma_{c}=|\vec{\tau}|-\left|\vec{\tau}_{0}\right|-\mu\left(\Delta \sigma_{n}-\Delta p\right),
$$

where $\vec{\tau}_{0}$ and $\vec{\tau}$ are the shear stresses before and after the stress change, respectively. If the slip direction on the failure plane of a future earthquake is known and only the change in the component of shear stress $\tau_{r}$ in the slip direction affects failure, then equation (6) reduces to equation (1),

$$
\Delta \sigma_{c}=\Delta \tau_{r}-\mu\left(\Delta \sigma_{n}-\Delta p\right) .
$$

$\Delta \tau_{r}$ and $\Delta \sigma_{n}$ can be estimated on any target plane of interest, for example using dislocation models of the source earthquake rupture. These target fault planes are typically assumed either to be optimally oriented (chosen to maximize $|\vec{\tau}| /\left(\Delta \sigma_{n}-\Delta p\right)$ ) or to correspond to preexisting fault planes of known orientation. This leaves $\mu$ and $\Delta p$ as the remaining unknowns. Laboratory studies suggest that most rock materials display a value of $\mu$ around 0.7 [Byerlee, 1978]. The instantaneous change in pressure $\Delta p$ must be estimated using some model of pore fluid response to stress change. In general, this response will be time-dependent because, if permeability permits, $\Delta p$ will change from the instantaneous "undrained state" that prevails immediately after the stress change to the "drained state" that is attained after fluids have had a chance to flow and reequilibrate. Throughout this study we ignore the time-dependent changes in pore fluid pressure and consider only the undrained state; this is an approach consistent with the majority of previous studies of Coulomb stress change.

\section{Pore Pressure Response Models}

\subsection{Isotropic Poroelastic Model}

Experimental observations suggest that in many cases changes in pore pressure in rock and soils are determined by changes in the mean stress [Skempton, 1954; Roeloffs, 1996]. For a homogeneous isotropic poroelastic medium [Rice and Cleary, 1976; Roeloffs, 1996], the relation between stress change and pore pressure change is

$$
\Delta p=B \Delta \sigma_{k k} / 3=B \Delta \sigma_{m},
$$

where $\sigma_{k k}$ indicates summation over the diagonal elements of the stress tensor and $\sigma_{m}=\sigma_{k k} / 3$ is the mean stress. The parameter $B$ is Skempton's coefficient, where $0 \leq B<1$. Sparse experimental determinations of $B$ for rocks indicate a range from 0.5 to 0.9 for granites, sandstones, and marbles [Rice and Cleary, 1976; Roeloffs and Rudnicki, 1985; Roeloffs, 1996]. If equation (3) applies to faults in the Earth, then

$$
\Delta \sigma_{c}=\Delta \tau_{r}-\mu\left(\Delta \sigma_{n}-B \Delta \sigma_{m}\right) .
$$

We subsequently refer to equation (8) as the isotropic model.

Recent studies of triggered seismicity have used the concept of an apparent coefficient of friction

$$
\mu^{\prime}=\mu\left(1-\Delta p / \Delta \sigma_{n}\right),
$$

for combining pore pressure and friction into a single variable. For the isotropic model, recasting equation 
(8) into the form of equation (2) yields

$$
\mu^{\prime}=\mu\left(1-B \Delta \sigma_{m} / \Delta \sigma_{n}\right) .
$$

According to (10), $\mu^{\prime}$ will change with location, as $\Delta \sigma_{m}$ changes, and with fault orientation, as $\Delta \sigma_{n}$ changes.

\subsection{Constant Apparent Friction Model}

Though it is clear either from (9) or (10), and from the original definition of $\mu^{\prime}$ by Byerlee [1992] and Hill [1993] that apparent friction can depend on stress state and fault orientation, many recent stress-triggering studies [Reasenberg and Simpson, 1992; Harris and Simpson, 1992; Stein et al., 1992; Deng and Sykes, 1997] have treated apparent friction as if it were a material constant with values $0 \leq \mu^{\prime} \leq 1$. Were $\mu^{\prime}$ an intrinsic material property, and time-dependent changes in $p$ were ignored, equation (9) would require that $\Delta p=k \Delta \sigma_{n}$ where $k$ is a constant. While we are unaware of any experimental or observational grounds for expecting that $\Delta p=k \Delta \sigma_{n}$ in natural fault zones, it might be expected on theoretical grounds. Simpson and Reasenberg [1994] suggest this relationship as one possible pore pressure model based on a ductile fault zone model proposed by Rice [1992]. For the Rice model, mean stress $\sigma_{m}=\sigma_{n}$, and thus $\Delta \sigma_{m}=\Delta \sigma_{n}$. Simpson and Reasenberg then employed the standard isotropic poroelastic relation (equation (7)) to relate stress change to pore pressure change, which leads to

$$
\mu^{\prime}=\mu(1-B)
$$

within the model fault zone. Equation (11) is the definition of apparent friction commonly used along with equation (2) in previous studies of Coulomb stress change (there are exceptions, including Li et al. [1987], Hudnut et al. [1989], Jaumé and Sykes [1992], Harris and Day [1993], and Simpson and Reasenberg [1994]). We will subsequently refer to equations (2) and (11) as the constant apparent friction model.

\section{Examples: Differences Between Pore Pressure Models}

Differences between the stress components driving pore pressure response, mean stress for the isotropic model, and normal stress for the constant apparent friction model, lead to differences in $\Delta \sigma_{\mathfrak{c}}$ between the two models for an arbitrary stress change. To illustrate this point, following Anderson [1951] and Sibson [1991], we calculate the response of these two models subjected to plane strain tectonic loading for reverse and strikeslip faults that are weaker than the surrounding crust and not optimally oriented for failure. We also perform similar analysis for an optimally oriented reverse fault. The assumptions of plane strain and tectonic loading allow for analytic solutions and easy comparison of the results. As mentioned above, the solutions obtained will be for the undrained state immediately after stress changes are applied; if fault zone permeability is low, this state will persist in time.

For Coulomb failure we are interested in the shear and normal stresses on a fault plane [Jaeger and Cook, 1979],

$$
\tau=\frac{1}{2}\left(\sigma_{1}-\sigma_{3}\right) \sin 2 \psi
$$

and

$$
\sigma_{n}=\frac{1}{2}\left(\sigma_{1}+\sigma_{3}\right)+\frac{1}{2}\left(\sigma_{1}-\sigma_{3}\right) \cos 2 \psi,
$$

where $\psi=\pi / 2-\beta, \beta$ is the angle between the fault plane and the greatest principal stress, and the principal components are numbered such that $\sigma_{1}>\sigma_{2}>\sigma_{3}$.

\subsection{Reverse Fault (Weak)}

First, consider stress changes imposed on a preexisting reverse fault of $\operatorname{dip} \beta$ that is weak with respect to its surroundings (Figure 1a). We assume that the least principal stress $\sigma_{3}$ is vertical and that its magnitude is fixed by the overburden weight so that $\Delta \sigma_{3}=0$ [e.g., Sibson, 1991]. For plane strain, $\Delta \sigma_{2}=\nu \Delta \sigma_{1}$ where $\nu$ is the undrained Poisson ratio. Under these constraints, an imposed stress change caused by an increment of tectonic loading can be characterized by a change in the greatest principal stress $\Delta \sigma_{1}$. From (12b) the change in normal stress is $\Delta \sigma_{n}=\Delta \sigma_{1}(1+\cos 2 \psi) / 2$, the change in mean stress is $\Delta \sigma_{m}=\Delta \sigma_{1}(1+\nu) / 3$, and from (12a) the change in shear stress is $\Delta \tau=\Delta \sigma_{1} \sin 2 \psi / 2$.

For the isotropic model, the change in Coulomb failure stress induced by an increment of tectonic stress change $\Delta \sigma_{1}$ can be written simply:

$$
\frac{\Delta \sigma_{c}}{\Delta \sigma_{1}}=\frac{\sin 2 \psi}{2}-\frac{\mu(1+\cos 2 \psi)}{2}+\frac{\mu B(1+\nu)}{3},
$$

where the first, second, and third terms on the right correspond to the contributions from changes in shear stress, normal stress, and pore pressure, respectively. For the constant apparent friction model,

$$
\frac{\Delta \sigma_{c}}{\Delta \sigma_{1}}=\frac{\sin 2 \psi}{2}-\frac{\mu(1-B)(1+\cos 2 \psi)}{2},
$$

where the first term is as in (13a), and the second term represents the combined contribution from the normal stress and pore pressure terms.

During an increment of increasing compressive load, normal stress increases which decreases $\sigma_{c}$, shear stress increases promoting failure and increasing $\sigma_{c}$, and mean stress increases. For $\beta=15^{\circ}$, appropriate for a lowangle reverse fault, the contribution of pore pressure change to the Coulomb failure stress for the isotropic model exceeds the small normal stress change and exceeds the shear stress contribution at high values of $\mu$ and $B$ (Figure 1b). For the constant apparent friction model, the pore pressure contribution can never 


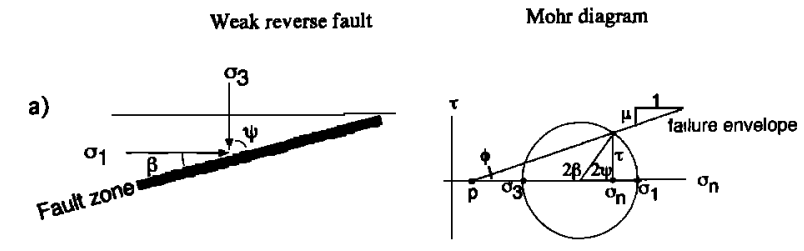

the plane is specified by the coefficient of friction so that $\tan 2 \psi=-1 / \mu$ (Figure $2 \mathrm{a}$ ). The sine and cosine terms in equations (12) can then be replaced with $\sin 2 \psi=1 / \sqrt{\mu^{2}+1}$ and $\cos 2 \psi=-\mu / \sqrt{\mu^{2}+1}$ [Jaeger and Cook, 1979; Engelder, 1993]. For the isotropic model the change in Coulomb failure stress induced by an increment of tectonic stress change is

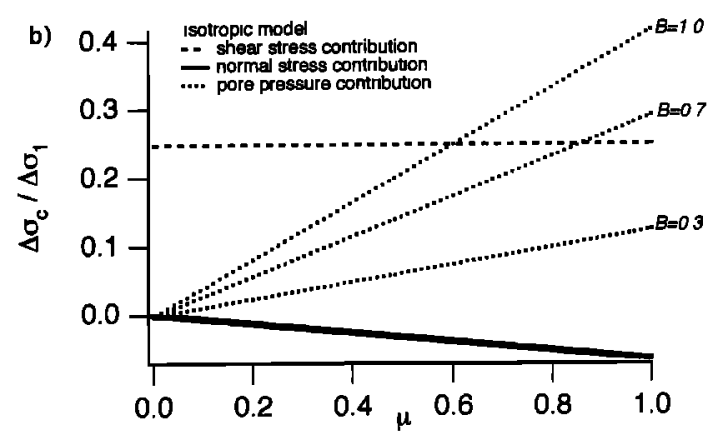

$$
\frac{\Delta \sigma_{c}}{\Delta \sigma_{1}}=\frac{1}{2 \sqrt{\mu^{2}+1}}-\frac{\mu}{2}\left[1-\frac{\mu}{\sqrt{\mu^{2}+1}}\right]+\frac{\mu B(1+\nu)}{3},
$$

where the first, second, and third terms on the right correspond to the contributions from changes in shear stress, normal stress, and pore pressure, respectively. As in the previous example an increase in compressive load increases normal stress which decreases $\sigma_{c}$,

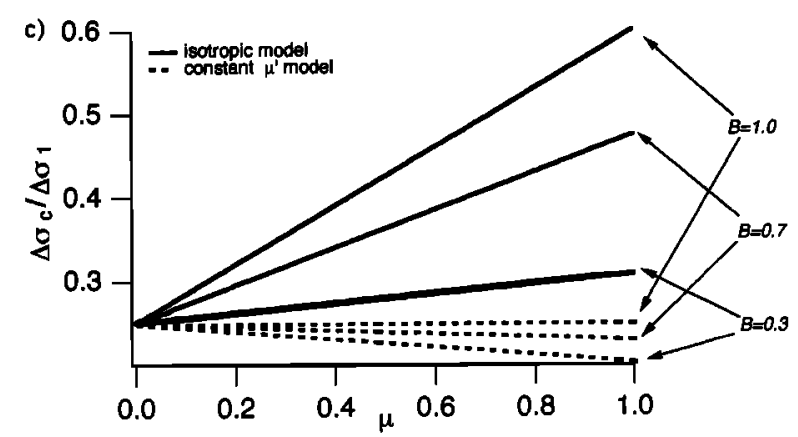

a)

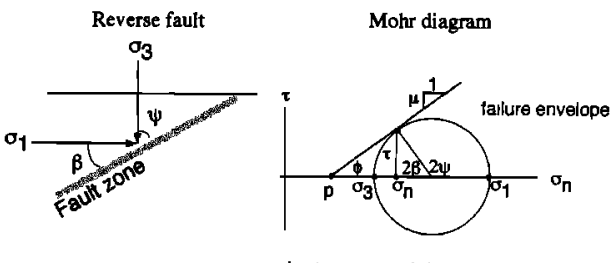

b)

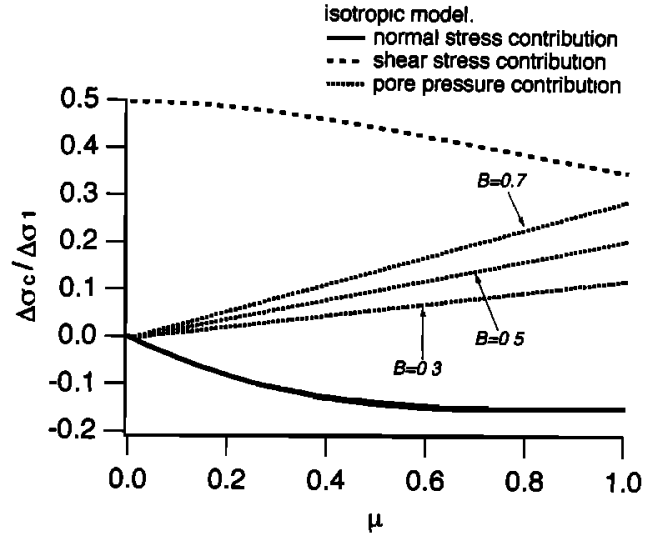

Figure 1. Weak reverse fault embedded in a stronger crust. (a) Angular relationships between stress directions and the fault in the real and Mohr planes, and the state of stress at failure; cohesion is ignored. The slope of the failure envelope is $\mu$. (b) Relative sizes of shear, normal, and pore fluid contributions to $\Delta \sigma_{c}$ per increment increase in $\sigma_{1}$ using the isotropic pore pressure model and $\psi=75^{\circ}\left(\beta=15^{\circ}\right)$. (c) Change in Coulomb failure stress per increment increase in $\sigma_{1}$ for the isotropic (equation (13a)) and the constant apparent friction (equation (13b)) pore pressure models as a function of $\mu$ and $B$.

exceed that from normal stress, and the shear stress contribution dominates. Thus the two models differ in the way $\Delta \sigma_{c}$ responds to changes in normal stress and pore pressure. Furthermore, for $0.7 \leq B<1.0$ and $0.6 \leq \mu \leq 0.8$, which are typical laboratory values of these constants [Byerlee, 1978; Roeloffs, 1996], $\Delta \sigma_{c}$ for the isotropic model is $61-112 \%$ larger than $\Delta \sigma_{c}$ for the constant apparent friction model at comparable values of $\mu$ and $B$ (Figure 1c). These differences decrease to zero as $\mu$ approaches zero.

\subsection{Reverse Fault in Optimal Orientation}

If faulting occurs on an optimally oriented plane, as is assumed in studies of stress-triggered aftershocks [Stein et al., 1992; King et al., 1994], then the orientation of

c)

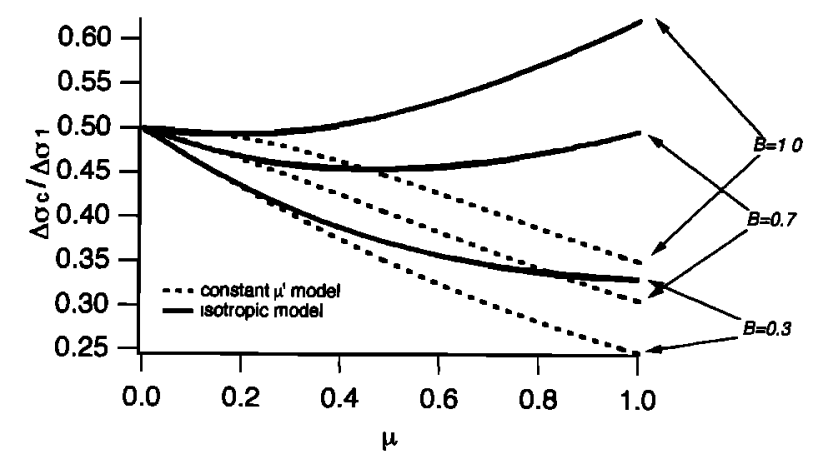

Figure 2. Optimally oriented reverse fault. (a) Angular relationships between stress directions and the fault in the real and Mohr planes, and the state of stress at failure; cohesion is ignored. The slope of the failure envelope is $\mu$. (b) Relative sizes of shear, normal, and pore fluid contributions to $\Delta \sigma_{c}$ per increment increase in $\sigma_{1}$ using the isotropic pore pressure model. (c) Change in Coulomb failure stress per increment increase in $\sigma_{1}$ for the isotropic (equation (14a)) and the constant apparent friction (equation (14b)) pore pressure models as a function of $\mu$ and $B$. 
shear stress increases, increasing $\sigma_{c}$, and mean stress increases (Figure $2 \mathrm{~b})$ ). Although pore pressure changes are always positive with the isotropic model, and can be larger than normal stress changes, the dominant contributor to changes in $\sigma_{c}$ is change in shear stress for reasonable values of $\mu$, even if $B$ is high (Figure $2 b$ ).

For the constant apparent friction model the change in Coulomb failure stress induced by an increment of tectonic stress change is

$$
\frac{\Delta \sigma_{c}}{\Delta \sigma_{1}}=\frac{1}{2 \sqrt{\mu^{2}+1}}+\frac{\mu(B-1)}{2}\left[1-\frac{\mu}{\sqrt{\mu^{2}+1}}\right] .
$$

Comparison of pore models at comparable values of $0.7 \leq B<1.0$ and $0.6 \leq \mu \leq 0.8$ shows that $\Delta \sigma_{c}$ of the apparent friction model is $19 \%$ to $49 \%$ larger than $\Delta \sigma_{c}$ of the isotropic model (Figure 2c).

\subsection{Strike-Slip Fault (Weak)}

In our final example we consider tectonic loading of a strike-slip fault which is weaker than the surroundings, namely, a fault of known but nonoptimal orientation (Figure 3a). This example is intended to be consistent with aspects of the tectonic setting of the San Andreas fault (SAF), where the crust surrounding the SAF may approach the threshold for reverse faulting and the greatest principal stress is at a high angle to the strike-slip fault [Zoback et al. 1987; Rice, 1992].

A requirement for strike-slip motion in this regime is that the strike-slip fault is weak relative to the adjacent reverse fault. For tectonic loading of a weak strikeslip fault plane in plane strain, we again assume that one of the principal stresses is vertical and fixed by the overburden, leading to $\Delta \sigma_{3}=0$. Tectonic loading is provided by changes in $\sigma_{1}$. In plane strain for this geometry, there is no strain in the direction parallel to the strike of the reverse fault $\left(\Delta \epsilon_{2}=0\right)$, leading to $\Delta \sigma_{2}=\nu \Delta \sigma_{1}$ and the shear and normal stresses on a vertical strike-slip fault are given by equations (12) with $\sigma_{3}$ replaced with $\sigma_{2}$.

For the isotropic model the change in Coulomb failure stress per increment of tectonic load on a fault plane of a particular orientation is

$$
\begin{gathered}
\frac{\Delta \sigma_{c}}{\Delta \sigma_{1}}=\frac{(1-\nu) \sin 2 \psi}{2}-\frac{\mu}{2}[1+\nu+(1-\nu) \cos 2 \psi] \\
+\frac{\mu B(1+\nu)}{3},
\end{gathered}
$$

where the three terms on the right correspond to the contributions from changes in shear stress, normal stress, and pore pressure, respectively. For the constant apparent friction model,

$$
\frac{\Delta \sigma_{c}}{\Delta \sigma_{1}}=\frac{(1-\nu) \sin 2 \psi}{2}-\frac{\mu(1-B)}{2}[1+\nu+(1-\nu) \cos 2 \psi] \text {. }
$$
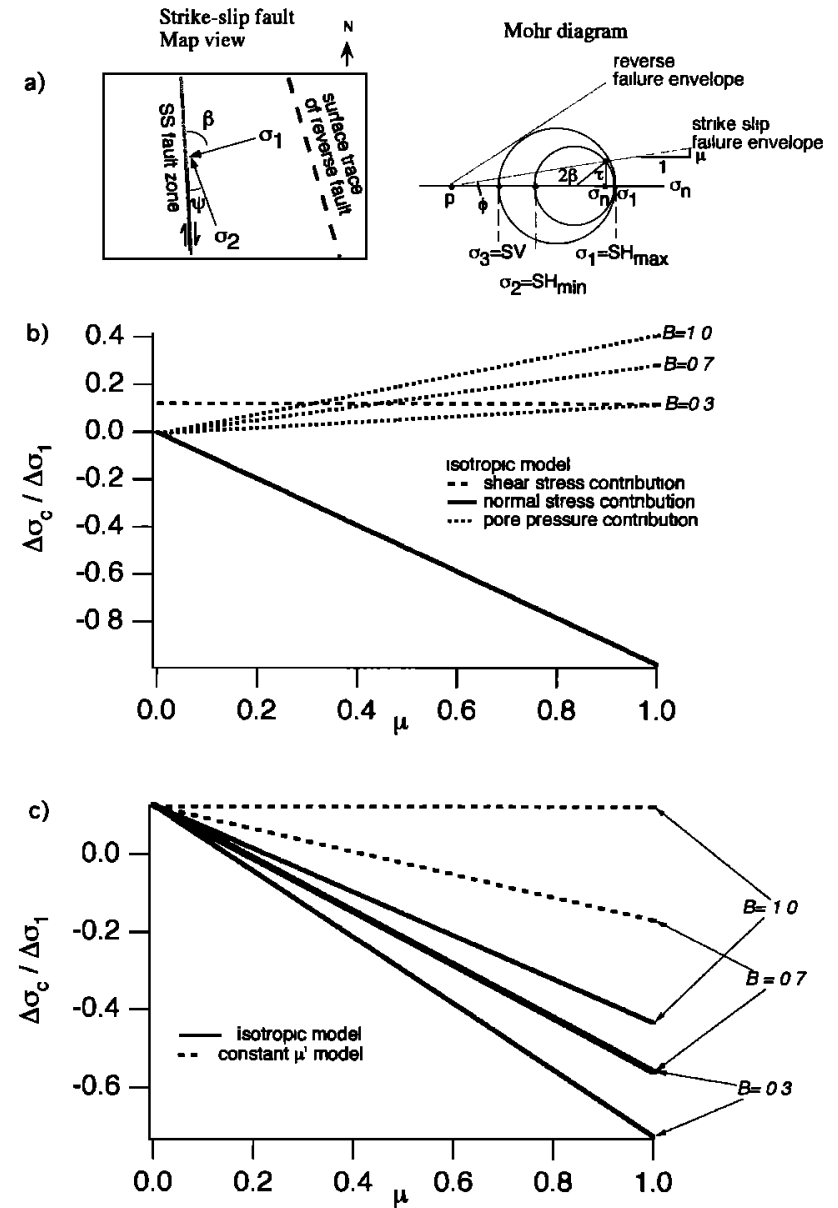

Figure 3. Weak strike-slip (ss) fault in a crust otherwise stressed for reverse failure. (a) Angular relationships between stress directions and the fault in the real and Mohr planes, and the state of stress at failure; cohesion is ignored. The slope of the failure envelope is $\mu$. The vertical, least horizontal and greatest horizontal principal stresses are denoted by $S_{v}, S H_{\min }$ and $S H_{m a x}$, respectively. (b) Relative sizes of shear, normal, and pore fluid contributions to $\Delta \sigma_{c}$ per increment increase in $\sigma_{1}$, using the isotropic pore pressure model and $\psi=10^{\circ}\left(\beta=80^{\circ}\right)$. (c) Change in Coulomb failure stress per increment increase in $\sigma_{1}$ for the isotropic (equation (15a)) and the constant apparent friction (equation (15b)) pore pressure models as a function of $\mu$ and $B$ for $\psi=10^{\circ}$.

As in the previous examples, during an increment of compressive loading, normal stress increases which reduces the Coulomb failure stress and stabilizes the fault, shear stress increases promoting failure and increasing $\sigma_{c}$, and $\sigma_{m}$ increases.

In the severely misoriented geometry of interest, e.g., $\psi=10^{\circ}$ (Figure 3), the change in fault-normal stress is large relative to changes in shear and mean stress, and the change in Coulomb failure stress is quite different for the two models. For the isotropic model normal stress dominates changes in $\sigma_{c}$ (Figure $3 \mathrm{~b}$ ) and tectonic loading actually moves the fault away from failure un- 
less $\mu$ is extremely low, regardless of the value chosen for $B$ (Figure 3c). In fact, taking $\psi=10^{\circ}$ as representative of the San Andreas fault system, if the pore pressure response to stress change is isotropic and homogeneous, then $\mu<0.23$ is required for tectonic loading to move the fault toward Coulomb failure, even if $B=1$. Although this constraint is based on somewhat different assumptions, it is not inconsistent with the inference that $\mu<0.2$ based on the absence of a heat flow anomaly adjacent to the SAF [Lachenbruch and Sass, 1992]. In contrast, $\mu$ in the constant apparent friction model is not so constrained and can have any value if $B=1$ (Figure 3c). Even if we restrict our attention to values of $\mu$ and $B$ which allow tectonic loading to increase the Coulomb failure stress $\left(\Delta \sigma_{c}>0\right)$, the differences between the two models are great. At values of $B=1.0$ and $\mu=0.2, \Delta \sigma_{c}$ of the apparent friction model is $725 \%$ larger than $\Delta \sigma_{c}$ for the isotropic model (Figure 3c).

\section{Discussion}

As indicated by the above examples, changes in Coulomb failure stress can depend significantly on the assumed relationship between stress change and pore pressure change. In the following we examine in more detail the physical implications of the constant apparent friction and isotropic models and conditions under which their application to fault failure and earthquake stresstriggering may be warranted.

\subsection{Uncertainties Regarding Pore Pressure Models of Natural Faults}

We do not know which, if either, of the two models discussed in this paper is appropriate for natural faults. There are arguments against applying either model to real fault zones. In the case of the constant apparent friction model, there are logical flaws in the original derivation of Simpson and Reasenberg [1994]. The Rice model on which the constant apparent friction model is based assumes a perfectly plastic solid undergoing incompressible flow in a fault zone contained within a rigid medium. Once the plastic yield threshold is reached the fault zone creeps at the constant yield shear stress $\tau_{r}$. As this yield stress is independent of normal stress, the Simpson and Reasenberg [1994] implementation of the Rice model does not permit a positive static shear stress change $\left(\Delta \sigma_{c}=\Delta \tau_{r}=0\right)$. Furthermore, the model fault would not allow brittle seismic failure given its ductile plastic nature. These deficiencies might be remedied to some degree by using a fault zone model with more complex rheological behavior, but then additional assumptions would be required.

Alternative arguments have been used to suggest that $\Delta p=k \Delta \sigma_{n}$ as assumed in the constant apparent friction model. Jaumé and Sykes [1996] argued that this equality is obtained for an undrained isotropic poroelastic medium [Scholz, 1990, equations 6.11 and 6.12], if changes in volumetric strain $\Delta \epsilon_{v}$ depend only on changes in the fault normal stress. Because isotropic poroelasticity requires $\Delta \sigma_{m} \propto \Delta \epsilon_{v}$ [Roeloffs, 1996], the Jaumé and Sykes [1996] argument is not general, and it applies only for stress changes where $\Delta \sigma_{m}$ is both proportional to $\Delta \sigma_{n}$ and insensitive to changes in other stress components. However, if inhomogeneity or anisotropy are introduced, poroelastic response can be quite different than that predicted by the homogeneous isotropic model.

J. R. Rice (oral communication, 1998) and Cocco and Rice [1999] have suggested that anisotropy, such as fractures in the plane of a preexisting fault zone, or contrasts in poroelastic properties between the fault zone and the country rock might lead to $\Delta p$ depending primarily on the changes in fault-zone normal stress, in which case $\Delta p=k \Delta \sigma_{n}$ would be the expected pore fluid response. In this regard it is worth noting that borehole measurements in the active Stillwater fault zone, Dixie Valley, Nevada, at $2.5-3 \mathrm{~km}$ indicate fault zone permeability dominated by fractures that are both optimally oriented for frictional failure and parallel to the overall fault zone [Hickman et al., 1998; Barton et al., 1998]. If these highly permeable fractures are much more compliant than other fractures in the fault zone, they may dominate the poroelastic response of this fault in the manner envisioned by Rice. Although the orientations of fluid-filled compliant fractures along active faults zones at depth are generally unknown, simulated laboratory faults, mismatched tensile fractures and natural joint surfaces have large fault-normal compliance [Brown and Scholz, 1986] because normal stress is supported by a few highly stressed asperities. If natural faults and associated fault-parallel fractures have a similar asperity structure and are hydraulically isolated from the adjacent country rock, then $\Delta p=k \Delta \sigma_{n}$ would be a plausible pore fluid response. In any case, in the absence of information on the pore pressure response of a particular fault zone, the constant apparent friction model should be used as an illustration of one possible pore fluid response [Simpson and Reasenberg, 1994].

Similarly, a homogeneous isotropic poroelastic model may not be appropriate for natural fault zones. Because they may have accommodated extremely large shear strains and are often associated with hydrothermal alteration, faults are not likely to have isotropic mechanical properties, or poroelastic properties that are identical to the surrounding country rock [Cocco and Rice, 1999]. Note that while some experimental observations demonstrate an isotropic poroelastic response [Rice and Cleary, 1976; Roeloffs, 1996], other measurements indicate that elastic stress/pore fluid pressure interactions are more complicated. For example, volumetric changes can be produced by changes in deviatoric stress alone, both in unfaulted [Wang, 1997] and faulted rocks [Woodcock and Roeloffs, 1996]. Furthermore, inelastic effects may alter the pore fluid pressure response of seismic fault zones near failure [Segall and Rice, 1995, and references therein]. 
It is not our intent here to argue that either the homogeneous isotropic poroelastic model or some anisotropic or inhomogeneous variant (leading to a useful definition of $\mu^{\prime}$ as a constant) is the correct model for describing faults in the Earth. The evidence is not yet in hand to decide whether these models or still other models are most appropriate. However, until better data are available, and so long as studies of Coulomb failure are formulated in terms of poroelastic response, we suggest that the homogeneous isotropic poroelastic model is a more clearly defined, and hence preferable, representation of poroelasticity than the constant apparent friction model.

\subsection{Apparent Friction in the Isotropic Model}

As discussed above, the assumptions that $\mu^{\prime}$ is simply related to $\mu$ and falls in the range $0 \leq \mu^{\prime} \leq 1.0$ are reasonable if apparent friction obeys equation (11); however these assumptions may be unreasonable for other pore models. The potentially complicated and nonunique relationships between $\mu^{\prime}$ and $\mu$ can be illustrated using our reverse fault example. Evaluating equation (10) for an optimally oriented reverse fault we find that

$$
\mu^{\prime}=\mu\left[1-\frac{2 B(1+\nu) \sqrt{\mu^{2}+1}}{3\left(\sqrt{\mu^{2}+1}-\mu\right)}\right] .
$$

This equation is nonlinear in $\mu$ and not of the simple form suggested by equation (11). If we examine the range of values for $\mu^{\prime}$, we see that for the isotropic model plausible values of $\mu$ and $B$ lead to both positive and negative values of $\mu^{\prime}$, in marked contrast to the apparent friction model (Figure 4). Negative values indicate that the pore pressure increase is large enough to overwhelm the normal stress increase. Although previous studies have interpreted low values of $\mu^{\prime}$ as indicative of low fault strength or high pore pressure (see below) this is not the case in our isotropic reverse fault example. For $\mu=0.75$ and $B=0.70$, which are reasonable values based on laboratory observations [Byerlee, 1978; Roeloffs, 1996] we obtain $\mu^{\prime}=-0.35$. Thus in the Earth, as in our example, low apparent friction does not necessarily require a low intrinsic frictional strength or a high pore pressure. Furthermore, while the apparent friction model predicts the same relation between friction and apparent friction in all tectonic settings, the isotropic model does not. Thus, even at constant $B$ and $\mu$, apparent friction in the isotropic model depends on the nature of the stress change and is not a material constant.

A similar conclusion about apparent friction can be reached for a case considered often in previous studies of $\Delta \sigma_{c}$ : the earthquake-induced stress change on optimally oriented planes. For the isotropic model, $\mu^{\prime}$ will not be a constant in the region surrounding the mainshock rupture because the stress field resulting from slip during the mainshock is not uniform. Rather, from (10)

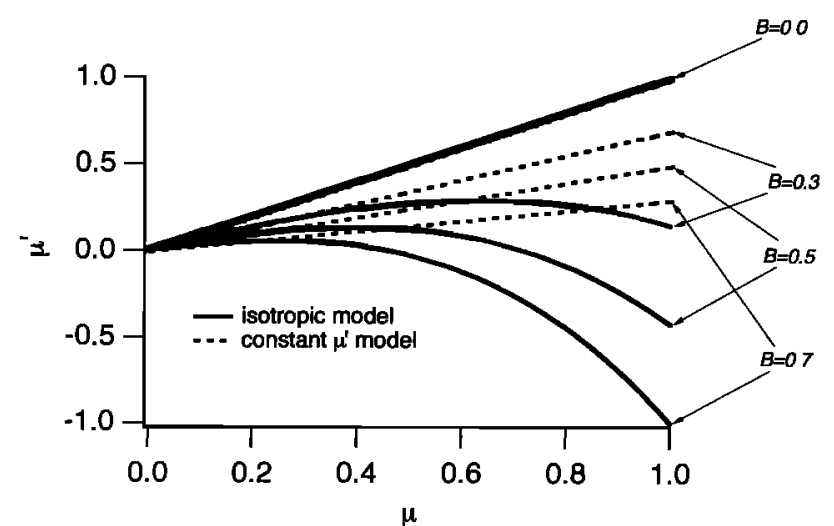

Figure 4. Variation in $\mu^{\prime}$ as a function of $\mu$ and $B$ for an optimally oriented reverse fault, according to the isotropic (equation 16) and constant $\mu^{\prime}$ (equation 11) models.

or (9) $\mu^{\prime}$ for the isotropic model will vary significantly about the mainshock rupture tip due to changes in the ratio $\Delta \sigma_{m} / \Delta \sigma_{n}$. For $\mu^{\prime}$ to be bounded requires that $\Delta \sigma_{n} \neq 0$. If an orientation exists for which $\Delta \sigma_{n}$ becomes vanishingly small or equal to zero, but for which $\Delta p$ is nonzero, then $\mu^{\prime} \rightarrow \pm \infty$. So for dislocationcalculated stress changes on optimally oriented planes, $\mu^{\prime}$ is expected to be spatially variable and can be either positive or negative and unbounded for the isotropic model. As a result, for this pore model, and for any pore model where $\Delta \sigma_{m}$ is not proportional to $\Delta \sigma_{n}, \mu^{\prime}$ can assume unrealistic values which have no physical significance.

\subsection{Could Observations of Stress-Triggered Seismicity Contain Information About Pore Pressure or Fault Strength?}

Inferences about fault strength and pore pressure are common in studies of stress-triggered seismicity. Often it is argued that low values of apparent friction reflect either low frictional strength or high pore pressure [Harris and Simpson, 1992; Stein et al., 1992; Hodgkinson et al., 1996; Deng and Sykes, 1996; Jaumé and Sykes, 1996; Stein et al., 1997; Gross and Bürgmann, 1998]. In fact, changes in Coulomb failure stress could not be used to infer the presence or absence of high fluid pressure even if $\mu$ were known. Unlike the original definition $\mu^{\prime}=\mu\left(1-p / \sigma_{n}\right)$ [Byerlee, 1992], $\mu^{\prime}$ in studies of change in Coulomb failure stress is defined in terms of differences in pore pressure and therefore contains no information on the magnitude of the ambient pore pressure. On the other hand, changes in Coulomb failure stress might contain information on pore pressure response (e.g., $B$ ) under some circumstances.

It is unclear at present whether analysis of changes in Coulomb failure stress can provide constraints on frictional strength or pore pressure response [Parsons et al., 1999]. For example, spatial distributions of triggered aftershocks [e.g., King et al., 1994] can be used as observational tests of Coulomb failure models. How- 

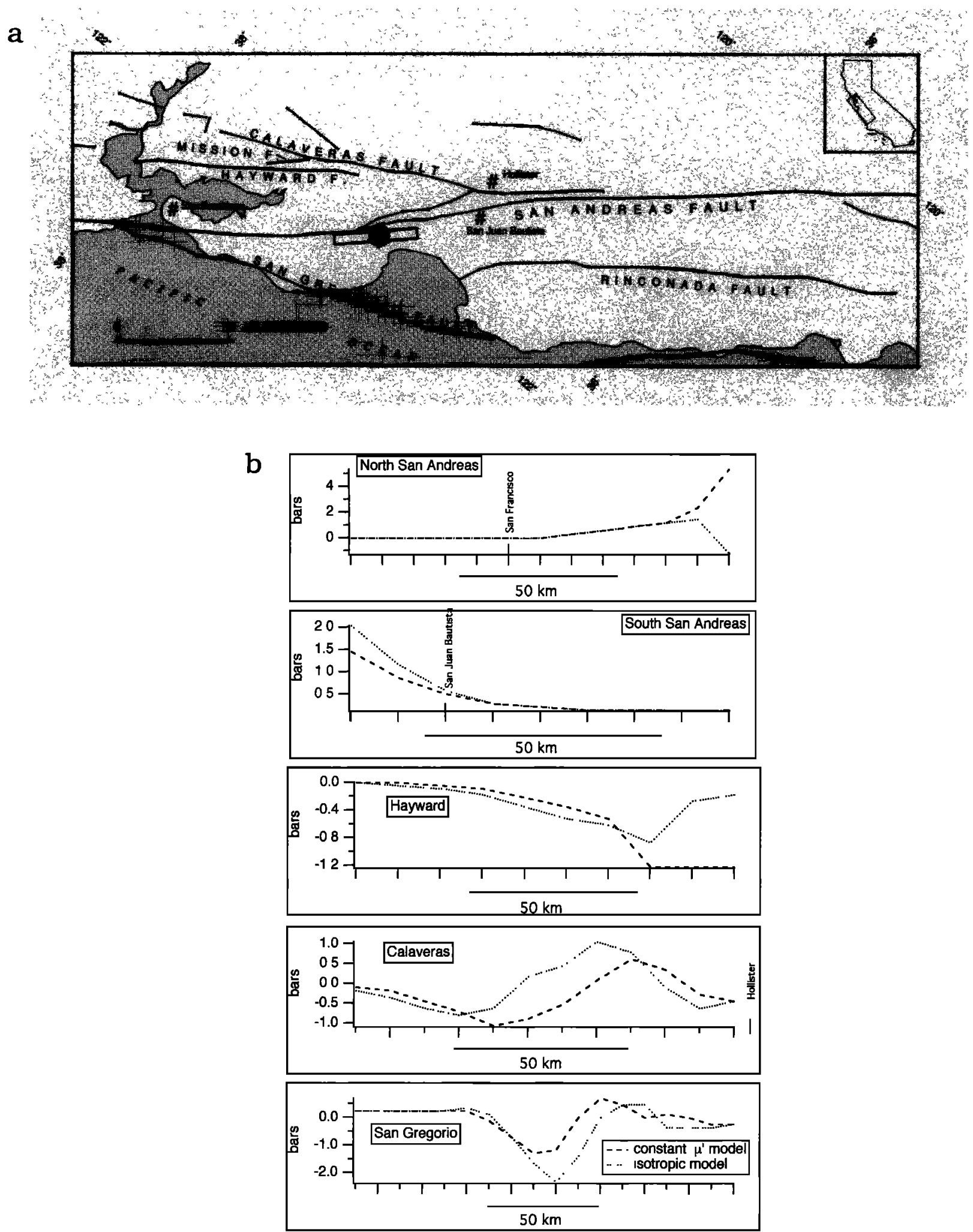

Figure 5. Change in Coulomb failure stress on central California faults induced by the 1989 Loma Prieta earthquake from Simpson and Reasenberg [1994]. (a) Study region showing the locations of fault segments. Solid circle is the epicenter of the Loma Prieta earthquake, and the rectangle is the rupture surface. (b) $\Delta \sigma_{c}$ calculated for the isotropic (dotted) and constant apparent friction (dashed) models assuming $B=1, \mu=0.75$, and using the slip distribution calculated by Lisowski et al. [1990]. The north and south San Andreas faults refer to those sections immediately to the north and south (respectively) of the Loma Prieta rupture. Horizontal tick marks are $10 \mathrm{~km}$. 
ever, in previous studies the location of an aftershock is successfully predicted based not on the magnitude of the Coulomb stress change at that location, but on the sign of the Coulomb stress change. Thus while the results of our study suggest that the magnitude of the Coulomb stress change depends strongly on choice of pore model, in practice distinguishing between various pore pressure models or between low and high friction requires spatial or temporal variations in the sign of the stress change predicted by various models. Until a clear link between changes in seismicity rate and the magnitude of the Coulomb stress change is established, distinguishing between pore models will only be possible in cases where the stress changes controlling pore pressure are large compared to shear stress changes (e.g., our misoriented reverse and strike-slip fault examples).

\subsection{Implications for Seismic Hazard}

In principle, the magnitude of the increase in failure stress on seismically active faults can be used to assess changes in earthquake probability and seismic hazard. Taking the two pore pressure models discussed in this paper as representative it is clear that change in failure stress will depend both on the models assumed and on the nature of the imposed stress changes. The choice of pore model could have significant effects on calculated Coulomb stress change, and therefore on predicted seismic hazard. This suggestion is supported by dislocation-calculated Coulomb stress change on central California faults induced by the Loma Prieta earthquake [Simpson and Reasenberg, 1994]. Over the limited sections of these faults where the Coulomb stress change is largest, there are first-order differences between the predicted $\Delta \sigma_{c}$ for the two models (Figure 5). For example, large differences in model predictions are seen on the central section of the Calaveras fault, the southern Hayward fault, the central San Gregorio fault and the San Andreas just north of the Loma Prieta rupture. This particular example is included in the present study to illustrate the importance of choice of pore pressure model in studies of $\Delta \sigma_{c}$; presumably, comparable differences in $\Delta \sigma_{c}$ would be observed in other studies of this type.

\section{Conclusions}

Given an uncertain knowledge of pore pressure response to stress change, we discourage the common practice of assuming that pore pressure response can be described by introducing an apparent coefficient of friction, a material constant incorporating both friction and pore pressure behaviors. Combining pore pressure response with intrinsic friction may impede progress in understanding the mechanical behavior and physical properties of seismic fault zones. Although arguments have been presented to suggest that a constant apparent coefficient of friction might be appropriate in some contexts, other pore pressure models, such as a homogeneous isotropic poroelastic response, may be more appropriate for describing earthquake faulting and aftershocks in some situations.

Laboratory measurements of porosity, permeability, poroelastic and poroinelastic responses to stress change would help determine the appropriate models for use in studies of stress triggering involving pore pressure. Although a few laboratory measurements of this kind have been made, both on simulated fault zones and core from active fault zones [Lockner and Byerlee, 1994; Wang, 1997; Morrow et al., 1994; Seront et al., 1998], these results have not been incorporated into models of triggered seismicity. Ideally, since core samples can fail to recover in situ macroscopic fractures which may dominate poroelastic response, and because such samples undergo stress relief during recovery, measurements of in situ permeability and porosity and monitoring of pore pressure within active faults during the seismic cycle [Hzckman et al., 1994] are needed. In the absence of physical measurement of fault zone properties, it would be helpful if stress-triggering studies could be used to distinguish between pore pressure response models.

Acknowledgments. NMB is indebted to Ruth Harris and Ross Stein for the opportunity to attend two SCEC conferences on stress triggering. Discussions with Susanna Gross, Jim Rice, Ruth Harris and Ross Stein are gratefully acknowledged. This paper was significantly improved in response to comments by Ruth Harris, Mary Lou Zoback, Rick Sibson, John Vidale, and Mark Zoback.

\section{References}

Anderson, E. M., The Dynamics of Faulting and Dyke Formation With Application to Britain, 206 pp., Oliver and Boyd, White Plains, N. Y., 1951.

Barton, C. A., S. H. Hickman, R. Morin, M. D. Zoback and R. Benoit, Reservoir-scale fracture permeability in the Dixie Valley, Nevada, geothermal field, paper presented at SPE/ISRM Eurock '98, Soc. of Pet. Eng./Int. Soc. of Rock Mech., Trondheim, Norway, 1998.

Brown S. R., and C. H. Scholz, Closure of rock joints, J. Geophys. Res., 91, 4939-4948, 1986.

Byerlee, J. D., Friction of rocks, Pure Appl. Geophys., 116, 615-626, 1978.

Byerlee, J. D., The change in orientation of subsidiary shears near faults containing pore fluid under high pressure, Tectonophysics, 211, 295-303, 1992.

Cocco, M., and J. R. Rice, Undrained fault pore pressure in Coulomb analysis determined by normal stress or first invariant?, Eos Trans. $A G U, 80(46)$, Fall Meet. Suppl., F1005, 1999.

Coulomb, C. A., Sur une application des règles de maximis et minimis à quelques problèmes de statique relatifs à l'Architecture, Acad. R. Sci. Mem. Math. Phys. Divers Savans, 7, 343-382, 1773.

Deng, J., and L. R. Sykes, Triggering of 1812 Santa Barbara earthquake by a great San Andreas shock: Implications for future seismic hazards in southern California, Geophys. Res. Lett., 23, 1155-1158, 1996.

Deng, J., and L. R. Sykes, Evolution of the stress field in southern California and triggering of moderate-size earthquakes: A 200-year perspective, J. Geophys. Res., 102, 9859-9886, 1997.

Engelder, T., Stress Regimes in the Lithosphere, 457 pp., Princeton Uni. Press, Princeton, N. J., 1993.

Gross, S. and R. Bürgmann, Rate and state of background 
stress estimated from the aftershocks of the 1989 Loma Prieta, California, earthquake, J. Geophys. Res., 103, 4915-4927, 1998.

Harris, R. A., Introduction to special section: Stress triggers, stress shadows, and implications for seismic hazard, J. Geophys. Res., 109, 347-358, 1998.

Harris, R. A., and S. M. Day, Dynamics of fault interaction: Parallel strike-slip faults, J. Geophys. Res., 98, 4461-4472, 1993.

Harris, R. A., and R. W. Simpson, Changes in static stress on southern California faults after the 1992 Landers earthquake, Nature, 360, 313-318, 1992.

Harris, R. A., R. W. Simpson and P. A. Reasenberg, Influence of static stress changes on earthquake locations in southern California, Nature, 375, 221-224, 1995.

Hickman, S., M. Zoback, L. Younker, and W. Ellsworth, Deep scientific drilling in the San Andreas fault zone, Eos Trans. AGU, 75, 137-140,142, 1994.

Hickman, S., M. Zoback, and R. Benoit, Tectonic controls on fault-zone permeability in a geothermal reservoir at Dixie Valley, Nevada, paper presented at SPE/ISRM Eurock '98, Soc. of Pet. Eng./Int. Soc. of Rock Mech., Trondheim, Norway, 1998.

Hill, D. P., A note on ambient pore pressure, fault-confined pore pressure, and apparent friction, Bull. Seismol. Soc. Am., 83, 583-586, 1993.

Hodgkinson, K. M., R. S. Stein, and G. C. P. King, The 1954 Rainbow mountain Fairview peak Dixie Valley earthquakes: A triggered normal faulting sequence, $J$. Geophys. Res., 101, 25,459-25,471, 1996.

Hudnut, K. W., L. Seeber, and J. Pacheco, Cross-fault triggering in the November 1987 Superstition Hills earthquake sequence, southern California, Geophys. Res. Lett., 16, 199-202, 1989.

Jaeger, J. C., and N. G. W. Cook, Fundamentals of rock mechanics, 585 pp., Chapman and Hall, New York, 1979.

Jaumé, S. C., and L. R. Sykes, Changes in state of stress on the southern San Andreas fault resulting from the California earthquake sequence of April to June, 1992, Science, 258, 1325-1328, 1992.

Jaumé, S. C., and L. R. Sykes, Evolution of moderate seismicity in the San Francisco Bay region, 1850 to 1993: Seismicity changes related to the occurrence of large great earthquakes, J. Geophys. Res., 101, 765-789, 1996.

King, G. C. P., R. S. Stein, and J. Lin, Static stress changes and the triggering of earthquakes, Bull. Seismol. Soc. Am., 84, 935-953, 1994.

Lachenbruch, A. H., and J. H. Sass, Heat flow from Cajon pass, fault strength and tectonic implications, J. Geophys. Res., 97, 4995-5015, 1992.

Li, V. C., S. H. Seale, and T. Cao, Postseismic stress and pore pressure readjustment and aftershock distributions, Tectonophysics, 144, 37-54, 1987.

Lisowski, M., W. H. Prescott, J. C. Savage, and M. J. Johnston, Geodetic estimate of coseismic slip during the 1989 Loma Prieta, California, earthquake, Geophys. Res. Lett., 17, 1437-1440, 1990.

Lockner, D. A., and J. D. Byerlee, Dilatancy in hydraulically isolated faults and the suppression of instability, Geophys. Res. Lett., 21, 2353-2356, 1994.

Morrow, C., D. Lockner, S. Hickman, M. Rusanov, and T. Röckel, Effects of lithology and depth on the permeability of core samples from the Kola and KTB drill holes, $J$. Geophys. Res., 99, 7263-7275, 1994.

Parsons, T., R. S. Stein, R. W. Simpson, and P. A. Reasenberg, Stress sensitivity of fault seismicity: A comparison between limited-offset oblique and major strike-slip faults, J. Geophys. Res., 104, 20,183-20,202, 1999.

Raleigh, C. B., J. H. Healy, and J. D. Bredehoeft, An experi- ment in earthquake control at Rangely, Colorado, Science, 191, 1230-1237, 1976.

Reasenberg, P. A., and R. W. Simpson, Response of regional seismicity to the static stress change produced by the Loma Prieta earthquake, Science, 255, 1687-1690, 1992.

Rice, J. R., Fault stress states, pore pressure distributions, and the weakness of the San Andreas Fault, in Fault Mechanics and Transport Properties of Rock: A Festschrift in Honor of W. F. Brace, edited by B. Evans and T.-f. Wong, pp. 475-503, Academic, San Diego, Calif., 1992.

Rice, J. R., and M. P. Cleary, Some basic stress diffusion solutions for fluid-saturated elastic porous media with compressible constituents, Rev. Geophys., 14, 227-241, 1976.

Roeloffs, E., Poroelastic techniques in the study of earthquake related hydrologic phenomena, Adv. Geophys., 37, 135-195, 1996.

Roeloffs, E., and J. W. Rudnicki, Coupled deformation diffusion effects on waterlevel changes due to propagating creep events, Pure Appl. Geophys., 122, 560-582, 1985.

Scholz, C. H., The Mechanics of Earthquakes and Faulting, 439 pp., Cambridge Univ. Press, New York, 1990.

Segall, P., and J. R. Rice, Dilatancy, compaction and slip instability of a fluid infiltrated fault, J. Geophys. Res., 100, 22,155-22,171, 1995.

Seront, B., T.-f. Wong, J. S. Caine, C. B. Forster, R. L. Bruhn and J. T. Fredrich, Lab characterization of hydromechanical properties of a seismogenic normal fault system, J. Struct. Geol., 20, 865-881, 1998.

Sibson, R. H., Loading of faults to failure, Bull. Seismol. Soc. Am., 81, 2493-2497, 1991.

Simpson R. W., and P. A. Reasenberg, Earthquake-induced static stress changes on central California faults, in The Loma Prieta, California Earthquake of October 17, 1989Tectonic Processes and Models, U.S. Geol. Surv. Prof. Pap., 1550-F, F55-F89, 1994.

Skempton, A. W., The pore pressure coefficients A and B, Geotechnique, 4, 143-147, 1954.

Stein, R. S., G. C. P. King, and J. Lin, Change in failure stress on the southern San Andreas fault system caused by the 1992 Magnitude $=7.4$ Landers earthquake, Science, 258, 1328-1332, 1992.

Stein, R. S., A. A. Barka, and J. D. Dieterich, Progressive failure on the North Anatolian fault since 1939 by earthquake stress triggering, Geophys. J. Int, 128, 594-604, 1997.

Terzaghi, K. V., Die Berechnung der Durchlassigkeitsziffer des Tones aus dem Verlauf der hydrodynamischen Spannumgserscheinungen, Sb. Akad. Wiss. Wien, 132, 105, 1923.

Townend, J., and M. D. Zoback, How faulting keeps the crust strong, Geology, 28, 399-402, 2000.

Wang, H. F., Effects of deviatoric stress on undrained pore pressure response to fault slip, J. Geophys. Res., 102, 17,943-17,950, 1997.

Woodcock, D., and E. Roeloffs, Seismically-induced water level oscillations in a fractured-rock aquifer well near Grants Pass, Oregon, Oreg. Geol., 58, 27-33, 1996.

Zoback, M. D., and J. H. Healy, Friction faulting and in-situ stress, Ann. Geophys.,2, 689-698, 1984.

Zoback, M. D., et al., New evidence on the state of stress of the San Andreas fault system, Science, 238, 1105-1111, 1987.

N. Beeler, S. Hickman, D. Lockner, and R. Simpson, U.S. Geological Survey, 345 Middlefield Road, MS 977, Menlo Park, CA 94025. (nbeeler@isdmnl.wr.usgs.gov)

(Received June 8, 1999; revised March 21, 2000; accepted March 30, 2000.) 